\title{
Identity, Collective Beliefs, and the Allocation of Resources*
}

\author{
THOMAS D. JEITSCHKO \\ Michigan State University, Michigan \\ SÉAMUS O'CONNELL \\ Maynooth College, Co. Kildare \\ ROWENA A. PECCHENINO \\ National University of Ireland, Maynooth
}

\begin{abstract}
Humans are social creatures that interact in a number of different and at least partially independent social settings, such as work, home, social and political organisations, and church. In each setting one has an identity, or set of identities, which one is called upon to achieve. To obtain and maintain an identity one must dedicate scarce resources. The benefits of expending these resources may be, among other things, income; wealth; success; prestige; power; security; respect; social acceptance; spiritual fulfillment; and salvation. To better understand how the individual makes his resource allocation decisions given the many possible interactions, both positive and negative, across his identities, changes in collective beliefs defining identity, and the substitutability or complementarity of identities, we develop a simple behavioural model of an individual whose personal identity is an amalgam of two identities. We interpret the model in the context of an individual with a secular and a religious identity.
\end{abstract}

\section{INTRODUCTION}

$\mathrm{H}$ umans are social creatures, and, as such, interact in a number of different and at least partially independent social settings, such as work, home, and social, political or religious organisations. In each of these settings

*We would like to thank Martin Ryan and the participants of the 2007 Irish Economics Association conference, and the seminar participants at the National University of Ireland, Galway. All remaining errors are ours alone.

Paper delivered at the Twenty-First Annual Conference of the Irish Economic Association, Bunclody, Co. Wexford, 25-27 May 2007. 
one has an identity, or set of identities whose actualisations require that one must put forth effort, that is dedicate scarce resources, be they of time or money, and use up psychological, spiritual, and human capital to increase the intensity of that effort. The benefits of expending these resources, of making these allocational choices (Sen, 2006), may be, among other things, income; wealth; success; prestige; power; security; respect; social acceptance; spiritual fulfillment; and salvation.

Since individuals have plural identities, the effort put forth concerning one identity may spill over positively or negatively onto the attainment of other identities. For example, the effort required to be successful in one's job may negatively affect one's family life, or the effort required to gain familial stability and security may positively affect one's social identity. Identities may also be complementary or substitutable. Thus, if complementary, something which makes one identity more easily obtainable, such as an improvement in childcare provision that lessens the effort required to raise one's children, frees resources that can be dedicated to attaining a complementary identity, such as one's work identity. However, if substitutable, something which makes one identity more easily obtainable may divert resources into that identity, work in the childcare example, perhaps leading to that identity dominating or displacing all others, such as parenting.

The identities to which one aspires are ideals, ${ }^{1}$ where the ideal, as perceived by the individual, is defined by collective beliefs. ${ }^{2}$ That is, what constitutes the ideal is based on one's beliefs about what the majority of members of one's reference group for that identity believe. Thus, this ideal could be inconsistent with one's own personal ideal and these ideals can change over time. However, to the extent that one's identities are social identities, it is what one believes the reference group believes that is determinant.

To put the components together, consider the following example. Suppose you wish to be successful in your new job. To succeed you believe that a majority of your co-workers and your boss believe that above and beyond doing your job well you must also be well liked by your co-workers and socialise with them on a regular basis, such as by spending Friday evenings with them at the pub. This belief about group beliefs about ideal behaviour could be reached by observing your boss and your co-workers, who come to their beliefs about ideal

\footnotetext{
1 The use of the term ideal may be a bit misleading since "ideal behaviour" may be consistent with a negative stereotype, such as those of lower castes are less capable (Hoff and Pandey, 2006) or that blacks are inferior to whites (Loury, 2002).

2 As discussed below, we borrow the notion of collective beliefs from Orléan (2004); however, in our context the focus is on individual allocation problems in light of these beliefs.
} 
behaviour in the same manner. Although you personally believe that the road to success should be based solely on your job performance and independent of extracurricular activities, you do your best to be convivial both on and off the job. Your co-workers do likewise irrespective of their individually held beliefs. But, should your religious identity require you to fast on Fridays, observe the Sabbath beginning at sundown, or attend services at the Mosque, or your family identity requires that you be home with your children or that you visit an aged parent, the effort you put forth to attain your work identity will negatively affect your ability to achieve your religious and family identities.

To better understand how the individual makes his resource allocation decisions given the many possible interactions, both positive and negative, across his chosen identities, changes in collective beliefs, and the substitutability or complementarity of identities, we develop a simple behavioural model of an individual whose personal identity is an amalgam of $N$ identities. Specifically, we model how individuals allocate resources among identities and how these resource allocation decisions are affected by changes, actual or perceived, in the individuals' social and economic environments.

\section{LITERATURE REVIEW}

The standard representation of an individual in economics is via a single preference ordering, a single identity that is fixed through time and not subject to individual choice. Individuals pursue their own self-interest, one that can be broadened out to have a social dimension, but the self, and satisfaction of that self, remains central to the analysis. Sen (1977) has challenged this as being too simplistic on a number of fronts. First, he argues (Sen 1985; 2002) that individual decision making cannot be characterised by optimising one's self-interest. Individuals have goals and make choices that are inconsistent with self-interest or personal gain no matter how broadly or narrowly defined. Rather, individuals are committed to particular social behaviours either to obtain a goal, such as social justice, which may bring them to harm in the hope of benefiting society, or to maintain the social structure within which they live by holding to societal behavioural norms (Sen 1997). Second, individuals do not have a single preference ordering but, rather, have multiple preference orderings, which could be interpreted as multiple identities, over a given set of choices. The individual then must have a preference ordering over the multiple orderings, but this ordering may not be complete. This incomplete ordering can lead to individuals exhibiting time inconsistent behaviours, as which ordering takes precedence at a moment in time may depend on any number of exogenous or endogenous factors. 
Akerlof and Kranton (2000; 2005) introduced the concept of identity and preferences based on achieving an assigned social identity rather than simply maximising one's narrow self-interest to mainstream economic discourse. While they maintain the concept of a single preference ordering and do not consider selfless, socially committed behaviours, they broaden the analysis to include the individual's social setting, how he is placed therein (by assignment rather than choice), and how he behaves to both be what society expects him to be and to minimise the cognitive dissonance of defying social expectations. Their models are closely related to models of socially referenced preferences, which also assume a single preference ordering and self-interested behaviour, such as Veblen (1934); Duesenberry (1949); Easterlin (1974); Frank (1985); and Clark and Oswald (1998); among others. A crucial difference, which may be more in interpretation than substance, is that in Akerlof and Kranton's analyses, individuals try to obtain an ideal identity rather than assessing their happiness relative to others in their reference group, or a sufficient statistic representing that reference group, per se. For Akerlof and Kranton, the closer one gets to the ideal, in terms of behaviour as well as physical characteristics, thereby decreasing cognitive dissonance, the greater the identity-linked benefits. A substantive difference is that reference groups may be a matter of choice. Identities for Akerlof and Kranton's agents are, by and large, not.

Kirman and Teschl (2004; 2006), Teschl (2006) and Horst, Kirman and Teschl (2006) acknowledge the strengths and weaknesses of standard economic theory and its extensions while taking seriously Sen's criticisms to better model identity and choice. Specifically, they agree that the standard representation of an economic agent is in terms of a given preference ordering. These preferences are fixed over time and, together with the specific constraints the agent faces, the agent attempts to maximise his utility. This gives a simple picture of the agent's identity at each moment in time by describing what the agent is. Introducing preferences for one's social identity expands rather than changes this simple view of a global and unchanging preference ordering, by adding to the description of the economic agent's identity more information as to where the agent is situated within a social space. To allow an individual to change, people choose to belong to social groups, rather than being assigned thereto, in order to become who they want to be and to realise their, not necessarily fixed, self-image. By choosing their social groups, people are consciously changing what and where they are right now, thus changing their preference ordering, to become who they would like to be in the future. The social group is a mechanism for people to acquire those characteristics they would like to have. However, people will not necessarily remain tied to their choices of social groups because these groups may 
themselves change over time. Ultimately, of course, who they want to be might also change as a consequence of their search for identity. But, this conscious and continuous change leads to incomplete preference orderings, and thus what will appear to be time inconsistent choices, thereby ruling out standard analysis.

Kirman and his colleagues model how an individual defines himself by choosing to change through time. That individual remains identifiable as a unique individual across change, as required by Davis's (2006) conception of the individual. This is in contrast to Parfitt (1971) who characterises the individual as a sequence of selves. Bazin and Ballet (2006) characterise the individual as having multiple selves simultaneously, like multiple identities. Their model also suggests that the individual's preference ordering will not be complete. Similar in emphasis are Schelling's (1985) analysis of multiple selves and Loewenstein's (2000) recognition of our inability to resist visceral urges. Both Schelling and Loewenstein suggest these visceral factors cause us to behave in a manner inconsistent with our true (or dominant) preferences, while only Schelling contends that individuals have multiple selves, each with his own preference ordering. Loewenstein, in contrast, contends that decisions are made by a single self with a single preference ordering, but effects of (visceral) states cause our lower order or primitive (irrational) nature to overwhelm our higher order (rational) nature when decisions are made under their influence.

In our model, individuals have a single self which is comprised of multiple social identities. In this way it bears some relationship to Hollander's (1990) model of social exchange and the Brekke et al. (2003) model of moral motivation. These papers ask why individuals take actions that are socially, if not what is thought to be individually, optimal. Hollander suggests it is because we seek the approval of our fellows. Brekke et al., suggest that it is because we, as individuals, want to maintain our self-image as socially responsible individuals, and define the socially responsible ideal via Kant's Categorical Imperative. Behaving to earn the approval of our fellows or to establish our self-image as socially responsible individuals may be consistent with collective beliefs about or social norms of ideal behaviour, that is, ideal identities. Here, however, we follow Orléan (2004), who provides a generic definition of collective beliefs. He defines a collective belief from the perspective of an individual such that "an individual $i$ believes that the group $G$ believes the proposition $Q$ if he believes that, in the majority, the members of the group believe that the group $G$ believes $Q$ " (p. 200). In our model the proposition $Q$ is the ideal identity, which will be a function of observable and unobservable characteristics as well as the individual's perceptions thereof. The observable characteristics can be considered Schelling saliences 
(Schelling, 1960), or focal points upon which individuals condition their actions.

\section{THE MODEL}

In our model agents' invest in identities to achieve a desired self-image. Following standard theory, the individual agent has a single preference ordering defined over $N$ distinct identities. Some identities may be latent, requiring no effort to obtain, while others may be dominant. The agent invests effort in identities to achieve his personal ideal. The individual identities can be in conflict. That is, building up one identity or reducing the cognitive dissonance between oneself and one's chosen identity, may move one further away from another identity goal thereby increasing the cognitive dissonance suffered in that identity. The utility maximising agent seeks to balance these forces. Observed behaviour may suggest social rather than self-interest optimisation and thus be contrary to self-interest as narrowly defined, as when achieving an identity consistent with one's self-image leads to personal discomfort or loss which, herein, would be the desired state as it would be consistent with the agent's ideal identity, or appear time inconsistent should ideals/collective beliefs or the individual's self-image change.

Let

$$
U\left(i^{1}-i^{1^{*}}, \ldots, i^{N}-i^{N^{*}}\right)
$$

represent an individual's utility defined over identities, his preference ordering over identities which defines his overall or composite identity. Utility/Identity is a function of his $n=1, \ldots, N$ identity relative to its ideal, $i^{n}-i^{n^{*}}$, for all $n$. Assume $U_{n}\left(\ldots, i^{n}-i^{n^{*}}, \ldots\right)>0(<0)$ for $i^{n}-i^{n^{*}}<0(>0)$, for all $n=1, \ldots, N$ and that $U_{n n} \leqslant 0$ for all $n=1, \ldots, N$. The sign of $U_{n m} n \neq m$ is positive if his $n$ and $m$ identities are complements, negative if they are substitutes, and zero if they are independent.

Assume that one's identities and the effort (resources expended) required to attain them are related as follows

$$
i^{n}-i^{n^{*}}=\hat{e}^{n}-e^{n^{*}}\left(v^{n}\right)
$$

where

$$
\hat{e}^{n}=e^{n}+\sum_{m \neq n} \beta^{m n} e^{m}
$$

where $\hat{e}^{n}$ is the effort the individual puts into his $n$ identity, which is the sum 
of his effort dedicated to his $n$ identity, $e^{n}$, and any spillover from effort dedicated to his other identities, $\beta^{m n} e^{m}$, for all $m$, where $\beta^{m n}<1$. $e^{n^{*}}\left(v^{n}\right)$ represents the individual's belief of the collective belief (Orléan, 2004) of the effort required to attain the ideal, where $v^{n}$ is a vector of conditioning variables (focal points, or Schelling salience (1960)) upon which beliefs about identity $n$ are conditioned. The perception of these conditioning variables and the collective beliefs implied can depend on context. In addition it is possible that perceived spillover effects can be augmented or diminished by collective beliefs. Thus, in general, $\beta^{n m}$ could be a function of $v^{n}$.

Substituting Equations (2) and (3) into the individual's utility function (1), the individual's task is to allocate his resources,

$$
e=\sum_{n} e^{n} e^{n} \geq 0
$$

optimally. We make the simplifying assumption that total effort available is fixed, but the model could be generalised to include effort intensity.

Substituting (2) and (3) into (1), the agent optimises

$$
U\left(e^{1}+\sum_{m \neq 1} \beta^{m 1} e^{m}-e^{i^{*}}\left(v^{1}\right), \ldots, e^{N}+\sum_{m \neq N} \beta^{m N} e^{m}-e^{N^{*}}\left(v^{N}\right)\right)
$$

subject to his resource and non-negativity constraints (4). The first-order conditions of the agent's problem are

$$
U_{n}+\sum_{m \neq n} U_{m} \beta^{m n}-\lambda+\mu^{n}=0, n=1, \ldots, N
$$

where $\lambda$ is the marginal disutility of effort, and $\mu^{n}$ is the multiplier on the non-negativity constraint. $\mu^{n} \geqslant 0$ if the optimal choice of $e^{n} \leqslant 0$ : all effort is put into the individual's other identities since the marginal disutility of effort exceeds the marginal utility of effort invested in that identity either directly or indirectly. Not all identities are mutually compatible.

To derive easily interpretable results, assume that the agent's effort is positive for only two identities, $S$ and $R$. Let $\beta^{R S}=\beta$ and $\beta^{S R}=\alpha$, and let $v^{S}=v$ and $v^{R}=\chi$. By resource constraint (4) this implies

$$
\begin{aligned}
& \hat{e}^{S}=e-e^{R}+\beta e^{R}=e-(1-\beta) e^{R} \\
& \hat{e}^{R}=e^{R}+\alpha\left(e-e^{R}\right)=e^{R}(1-\alpha)+\alpha e
\end{aligned}
$$

and an effective utility function of 


$$
U\left(e-(1-\beta) e^{R}-e^{S^{*}}(v), e^{R}(1-\alpha)+\alpha e-e^{R^{*}}(\chi)\right) .
$$

The agent's optimal choice of $e^{R}$ is defined by

$$
-(1-\beta) U_{1}+(1-\alpha) U_{2}=0
$$

where $U_{1}$ is the marginal utility of effort invested in identity $S$, and $U_{2}$ is the marginal utility of effort invested in identity $R$. The agent allocates his resources so that the marginal rate of substitution between identity $S$ and identity $R$ equals the marginal rate of transformation, which is defined by the effort spillovers.

While we analyze the individual's problem as an optimisation exercise, we do so to determine in which direction resources will be reallocated as a result of exogenous changes in an individual's environment. To explore the interactions across identities as a result of changes in this environment changes in the conditioning variables that cause collective beliefs to change, and the effects of substitutability or complementarity of identities - we totally differentiate (9).

$$
\begin{aligned}
& {\left[(1-\beta)^{2} U_{11}-(1-\beta)(1-\alpha) U_{12}+(1-\alpha)^{2} U_{22}\right] d e^{R}=} \\
& {\left[-I_{1}+(1-\beta) U_{11} e^{R}-(1-\alpha) U_{21} e^{R}\right] d \beta+\left[-(1-\beta) U_{11}+(1-\alpha) U_{12}\right] d e^{S^{*}}+} \\
& {\left[-(1-\beta) U_{11}+(1-\alpha) U_{21}\right] e^{S^{* \prime}}(v) d v+} \\
& {\left[(1-\beta) U_{12}\left(e-e^{R}\right)+U_{2}-(1-\alpha) U_{22}\left(e-e^{R}\right)\right] d \alpha+\left[(1-\alpha) U_{22}-(1-\beta) U_{21}\right] d e^{R^{*}}+} \\
& {\left[(1-\alpha) U_{22}-(1-\beta) U_{21}\right] d e^{R^{* \prime}}(\chi) d \chi+\left[(1-\beta) U_{11}+\left((1-\beta) \alpha-(1-\alpha)^{\prime} U_{12}-(1-\alpha) \alpha U_{22}\right] d e\right.}
\end{aligned}
$$

From (10) the following three results are straightforward to derive. Proofs can be found in the Appendix.

Proposition 1: If achieving an individual's $\mathrm{R}(\mathrm{S})$ ideal identity becomes relatively more demanding $\left(e^{R^{*}}(\chi)\right.$ rises for $\chi$ constant $\left(e^{S^{*}}(v)\right.$ rises for $v$ constant)) and if his identities are complementary or independent, then he reallocates resources away from his $\mathrm{S}(\mathrm{R})$ identity to his $\mathrm{R}(\mathrm{S})$ identity. If identities are substitutes, the individual may invest more resources in the relatively less demanding $\mathrm{S}(\mathrm{R})$ identity. 
Proposition 2: Assume $e^{R^{*}}(\chi)^{\prime}<0\left[e^{S^{*}}(v)^{\prime}<0\right]$. If a component of the vector of conditioning variables, $\chi(v)$, increases, then if identities are complements, an individual will reallocate effort away from his $\mathrm{R}$ (S) identity to his $\mathrm{S}$ (R) identity to obtain the best overall balance. If identities are substitutes, an individual may reallocate resources from his $\mathrm{S}(\mathrm{R})$ to his $\mathrm{R}(\mathrm{S})$ identity.

Proposition 3: An increase in $\beta(\alpha)$, the $\mathrm{R}$ to $\mathrm{S}$ ( $\mathrm{S}$ to $\mathrm{R}$ ) spillover leads an individual to increase resources dedicated to $\mathrm{R}(\mathrm{S})$ effort if identities are complements, and may lead to a decrease in or a mitigating effect on $\mathrm{R}(\mathrm{S})$ effort if identities are substitutes.

Since an individual's resources are limited and since his goal is to attain the best overall identity possible given this limitation, he must allocate his resources taking into account complementaries across identities, substitutability across identities, and spillovers of effort, both positive and negative, across identities. When identities are complementary individuals try to achieve a balance between them. So, if one becomes more difficult to achieve, directly or via a change in conditioning variables, the agent will reallocate resources away from the relatively easily attained identity to the relatively more difficultly attained identity to maintain a balance. But, if identities are strong substitutes the individual may find it best to concentrate on the relatively more easily achieved identity, thereby reducing the resources dedicated to the identity which is now more difficult to achieve. The degree of complementarity or substitutability across identities is specific to an individual. Thus, two agents with the same set of identities could behave very differently in response to a change in collective beliefs if for one identities are complements and if for the other identities are strong substitutes. For example, for some $S$ and $R$ may be complementary, leading them to try to obtain a $S / R$ balance, while for others they are strong substitutes, leading them to concentrate either on $S$ or on $R$, but not both. ${ }^{3}$ Effort spillover effects, which essentially weaken or tighten the resource constraint, may intensify or weaken the complementarity/substitutability effects. Thus, if there are positive spillovers from $S$ to $R$ and $S$ and $R$ are substitutable identities, one may still have both even though a predominance of effort goes to achieving one's $S$ identity. However, if there are negative spillovers from $S$ to $R$ and $S$ and $R$ are substitutable identities, the incentive to concentrate all one's resources on $S$ is strengthened. Thus, to understand behaviour, it is essential to determine whether identities are complements or substitutes, the strength

${ }^{3}$ For this example it may be useful to think of $S$ as work and $R$ as life. 
of their substitutability when they are substitutes and whether effort spillovers are positive or negative.

\section{INTERPRETATION OF MODEL FOR SECULAR AND RELIGIOUS IDENTITIES}

For concreteness we will now interpret identity $R$ to be a religious identity and identity $S$ to be a secular identity and interpret the results of the model in this light. One's religious identity could be derived from your membership in a faith community (which may or may not include your family), while one's secular identity could be derived from work, friendships, political and social group memberships, or residential community.

Following Proposition 1, assume that achieving an individual's religious identity becomes relatively more demanding, for example, as a result of changes in work rules or times or locations of religious services that make it more difficult for one to practice one's religion. Thus, if identities are complementary, so overall identity is enhanced by putting effort into both, the individual will reorganise his time so that he can still attend religious services or pray at the prescribed times, although, perhaps not as often or at all required times. He will not be able to get as close to either ideal, but will attain a balance between the two. Thus, many first generation immigrants from predominantly Muslim to predominantly Christian countries, while not abandoning their faith, concentrated their effort on becoming materially successful in their adopted country (Waldman, 2005), remaining Muslim but practicing at a much reduced level. However, if identities are substitutes, an individual may find the barriers to religious practice, such as observing the call to prayer for Muslim teenagers in US public schools (DuLong, 2005), or openly declaring one's Christianity and living accordingly for a teenaged American Evangelical in a highly secularised, permissive environment (Goodstein, 2006), are so high that he is better off allocating effort in the secular realm, that is, concentrating resources (both material and psychic) on his non-religious identity.

Suppose instead it becomes more difficult for an individual to attain his secular identity and his identities are substitutes. Then he may choose to dedicate more of his resources to his religious identity. Consider the situation of a young graduate in a country with high youth unemployment, such as France, today. If jobs are scarce and discrimination against young workers or young workers of specific ethnic backgrounds is rife (even when jobs are plentiful), then he may find that his overall identity is best achieved by reallocating resources away from his secular identity to his religious identity. Thus, "self-identification as a Muslim is in many cases a consequence of an 
ethnic solidarity maintained or preserved by the socio-economic conditions of segregation. Avoiding the stigma attached to segregation requires dissociation from the dominant culture to the extent possible, reclaiming the stigmatised identity, and inverting this stigmatisation into a positive attribute. Marginalised ethnic or religious groups take both the closeness imposed upon them by the dominant culture and the binary and essentialist categories with which the dominant culture characterises them, and turns these disadvantages into positive elements of identity" (Cesari, 2005).

Now, following Proposition 2, consider an increase in one of the conditioning variables that leads to an increase in the effort required to meet the ideal religious identity. For example, suppose that there has been a crisis in the church as a result of perceived failures in church leadership, or that there were shifts in official doctrine that are found unpalatable by the laity, or that what had been accepted behavioural norms are no longer so because the reference group has changed. Clearly, to be a good Catholic, for example, as defined by what the individual Catholic believes the majority of Catholics believe to be behaviour befitting a good Catholic, will depend, in part, on the moral teachings of the church. If the behaviour of members of the church hierarchy contradicts these moral teachings, then the collective belief of ideal behaviour can change since the conditioning variable, the focal point, has changed. Or the collective belief can remain constant, since members of the church can see beyond the failings of their current leaders. In either case, the effort required to achieve the ideal would increase. The response would be to redouble one's effort, when identities are complements, or to leave the church or limit practice by reducing both time and money dedicated, if identities are substitutes. Osoba (2004) shows that charitable contributions to the Catholic Church and its related charities fell as a result of the paedophilia scandals in the United States. Lothian (2000) attributes the reduction in Mass attendance in the United States, Britain, Ireland and the Netherlands to the Vatican II liturgical reforms, while Fuller (2002) finds the drift away from the Catholic Church in Ireland a result, in part, of Ireland's greater integration in Europe and participation in the world economy.

Focal points defining identity can shift as a result of political, economic, or social change. For example, Crouch (2000) traces the role of religion in European politics following the Second World War in Europe. In the immediate post-war period there was a significant political shift towards a Christian Democratic governing philosophy based on a rejection of both liberalism and socialism. Further, in recognition of the harm animosities based on religious and ethnic differences had caused, churches came together to stress the similarities of their beliefs. Christians reached out to each other and to tolerant non-believers to ensure the continued existence of stable democracies not riven by sectarian difference. A distinct religious identity 
defined in part by, for example, being Catholic and not being Lutheran, once perceived as an asset, was now perceived as a liability. What was instead important was to be a good citizen, where good was defined by commonly held religious (Judeo-Christian) values. That is, a focal point determining collective beliefs shifted. This led to a reduction in the effort required to attain one's religious ideal and less distinction between religious and secular identities. The enhanced similarity of identities leads to an increase in resources dedicated to achieving the secular ideal while resources dedicated to religious practice and, thereby, the church, dwindle since in achieving one the other is achieved. In contrast, the religious focal point can remain fixed while the secular focal point loses definition. Munshi and Wilson (2007) show that in small communities in the Midwest of the United States jobs were often obtained via ethnic networks - secular focal points. These networks were often associated with a migrant church which provided the religious focal point of people's lives. While the ethnic networks no longer exist as mechanisms of job provision and the link between church and ethnic origins has dissipated, the church remains a focal point of community life. Investments in the life of the church generate both religious and secular identity again via a blurring of identity definitions.

Spillover effects across identities can also fundamentally affect behaviour. Consider first positive spillovers, so that one's effort in the religious sphere has a positive spillover onto one's secular effort, and vice versa. Gruber (2005) finds that religious practice is good for you both socially and economically. This is consistent with Weber's (1950) Protestant work ethic which suggested that hard work and thrift led both to temporal and eschatological rewards. But, should the spillover effects be negative, say an increase in religious effort offsetting secular effort, the individual may choose to forego all religious effort. This could be the case if practicing one's religion leads to (partial) social ostracism which one must work to overcome. Alba (2005) finds evidence of this in relation both to Catholic immigrants to the United States in the first half of the twentieth century as well as Muslim immigrants to Europe today. In both cases some immigrants found that to get ahead materially they had to reject their traditional religious identities, a task made more or less difficult by ethnic characteristics which others use to impose or infer identity.

\section{CONCLUSIONS}

We have developed a model in which agents have a single preference ordering defined over identities. To achieve desired identities individuals engage in behaviours, take actions that draw on their personal resources, be 
they of time, money, or psychic energy. Identities are defined by collective beliefs, and may, although they need not, place the good of society over the good of the individual. The identities an individual strives to obtain may be complementary, substitutable, or independent of each other, and behaviours engaged in may be beneficial or detrimental to other identities. Perhaps paradoxically, although attaining one's desired identity brings the individual happiness, utility, it can also bring personal discomfort or material loss. If this is the case, psychic gains, which are difficult to observe or measure, overwhelm the material or physical losses. Clearly, behaviours more consistent with what is usually recognised as the maximisation of self-interest which generate physical comfort and material gain are also possible, and can coexist with more selfless behaviours by the same individual.

In modern society individuals are amalgams of many, often conflicting, identities. Social policies designed to create a cohesive, multicultural society in which, for example, secular and religious spheres coexist in a positive synergistic relationship, can lead to unintended consequences if complementarities, substitutability, and spillover across identities are not taken into account. Specifically, policies must recognise that while for some secular and religious identities may be complements, for others they are substitutes. Why they are one or the other may depend on political, social, ethnic or economic structures in the society. Thus, policies designed to induce assimilation, such as requiring immigrants to learn to be Danish or Dutch and to accept Danish or Dutch social and cultural beliefs (which may be contrary to one's religious beliefs) or requiring one to abandon one's traditional (religiously mandated) dress (head-scarves, turbans), are based on the, implicit, assumption that secular and religious identities are complements. However, if instead these identities are substitutes, such policies may actually lead not to assimilation but rather to alienation from the dominant culture as immigrants substitute away from the now more costly secular identity to their religious identity. The different and ever shifting identities of the individuals who make up society is a difficult construct upon which to base policy, but it may be necessary to do just that.

\section{REFERENCES}

AKERLOF, G. A., and R. E. KRANTON, 2000. "Economics and Identity", Quarterly Journal of Economics, Vol. 115, No. 3, pp. 715-753.

AKERLOF, G. A., and R. E. KRANTON, 2005. "Identity and the Economics of Organizations", Journal of Economic Perspectives, Vol. 19, No. 1, pp. 9-32.

ALBA, R., 2005. "Bright and Blurred Boundaries: Second-Generation Assimilation and Exclusion in France, Germany and the United States", Ethnic and Racial Studies, Vol. 28, No. 1, pp. 20-49. 
BAZIN, DAMIEN and JÉRÔME BALLET, 2006, “A Basic Model for Multiple Self”, The Journal of Socio-Economics, Vol. 35, pp. 1050-1060.

BREKKE, K., S. KVERNDOKK and K. NYBORG, 2003. "An Economic Model of Moral Motivation”, Journal of Public Economics, Vol. 87, pp. 1967-1983.

CESARI, J., 2005. "Ethnicity, Islam and les banlieues: Confusing the Issues", in SSRC Forum: Riots in France, http://riotsfrance.ssrc.org/, November 30.

CLARK, A. E., A. J. OSWALD, 1998. Comparison-concave Utility and Following Behaviour in Social and Economic Settings, Journal of Public Economics, Vol. 70, pp. 133-155.

CROUCH, C., 2000. "The Quiet Continent: Religion and Politics in Europe", The Political Quarterly, Vol. 71, No. 1, pp. 90-103.

DAVIS, JOHN B., 2006. "Social Identity Strategies in Recent Economics", Journal of Economic Methodology, Vol. 13, No. 3, pp. 371-390.

DUESENBERRY, J., 1949. Income, Saving, and the Theory of Consumer Behavior, Cambridge, MA: Harvard University Press.

DuLONG, J., 2005. "The Imam of Bedford-Stuyvesant", Saudi Aramco World, Vol. 56, No. 3, pp. 20-23.

EASTERLIN, R. A., 1974. "Does Economic Growth Improve the Human Lot? Nations and Households in Economic Growth", in P. A. David and M. W. Reder, (eds.), Essays in Honour of Moses Abramovitz, New York: Academic Press, Inc., pp. 89-125.

FRANK, R. H., 1985. "The Demand for Unobservable and Other Nonpositional Goods", American Economic Review, Vol. 75, No. 1, pp. 101-116.

FULLER, L., 2002. Irish Catholicism Since the 1950s: The Undoing of a Culture, Dublin: Gill and Macmillan.

GRUBER, J., 2005, "Religious Market Structure, Religious Participation, and Outcomes: Is Religion Good for You?" Advances in Economic Analysis and Policy, Vol. 5, No. 1, Article 5.

GOODSTEIN, L., 2006. "Evangelicals Fear the Loss of Their Teenagers", New York Times, October 6.

HOFF, K. and P. PANDEY, 2006. "Discrimination, Social Identity, and Durable Inequalities", American Economic Review Papers and Proceedings, Vol. 206, No. 2, pp. 206-211.

HOLLANDER, HEINZ, 1990. "A Social Exchange Approach to Voluntary Cooperation", American Economic Review, Vol. 80, pp. 1157-1167.

HORST, ULRICH, ALAN KIRMAN and MIRIAM TESCHL, 2006. "Changing Identity: The Emergence of Social Groups, GREQAM Working Paper 2006-51.

KIRMAN, A. and M. TESCHL, 2004. "On the Emergence of Economic Identity", Revue de Philosophique Économique, Vol. 9, No. 1, pp. 59-86.

KIRMAN A. and M. TESCHL, 2006, "Searching for Identity in the Capability Space", Journal of Economic Methodology, Vol. 13, No. 3, pp. 299-325.

LOEWENSTEIN, GEORGE, 2000. "Emotions in Economic Theory and Economic Behavior", American Economic Review, Vol. 90, No. 2, pp. 426-432.

LOTHIAN, J., 2000. "Novus ordo Missae: The Record After Thirty Years", Homeletic \& Pastoral Review, Vol. 51, No. 1, pp. 26-31.

LOURY, G., 2002. The Anatomy of Racial Inequality, Cambridge, MA: Harvard University Press. 
MUNSHI, K. and N. WILSON, 2007. "Identity and Occupational Choice in the American Midwest", Brown University Working Paper.

ORLÉAN, A., 2004. "What is a Collective Belief?" in Paul Bourgine and Jean-Pierre Nadal, (eds.), Cognitive Economics: an Interdisciplinary Approach, Berlin: Springer, pp. 199-212.

OSOBA, B., 2004. "Sins of the Father: The Impact of Sexual Abuse on Faith-based Charitable Giving", Working Paper, University of Texas El Paso.

PARFIT, D., 1971. "Personal Identity", Philosophical Review, Vol. 80, No. 1, pp. 3-27.

SCHELLING, T. C., 1977 (1960). The Strategy of Conflict, Oxford: Oxford University Press.

SCHELLING, T. C., 1985. "Enforcing Rules on Oneself", Journal of Law, Economics and Organization, Vol. 1, No. 2, pp. 357-374.

SEN, A., 1977. "Rational Fools: A Critique of the Behavioral Foundations of Economic Theory", Economica, Vol. 40, No. 159, pp. 241-259.

SEN, A., 1985, "Goals, Commitment and Identity", Journal of Law, Economics and Organization, Vol. 1, No. 2, pp. 341-355.

SEN, A., 1997, "Maximization and the Act of Choice", Econometrica, Vol. 65, No. 4, pp. $745-779$.

SEN, A., 2002, Rationality and Freedom, Cambridge, MA: Belknap, Harvard University Press.

SEN, A., 2006, Identity and Violence: The Illusion of Destiny, New York: W.W. Norton \& Company.

TESCHL, MIRIAM, 2006. "Personal Identity Decisions for Examining Change", Working Paper, Robinson College, University of Cambridge, UK.

VEBLEN, T., 1934. The Theory of the Leisure Class, New York: Modern Library.

WALDMAN, A., 2005. "Seething Unease Shaped British Bombers' Newfound Zeal", New York Times, July 30.

WEBER, M., 1950 [1905], The Protestant Ethic and the Spirit of Capitalism, T. Parsons, translator. New York: Scribners. 


\section{APPENDIX}

The following derivations hold at an interior optimum.

Let $\Delta=(1-\beta)^{2} U_{11}-(1-\beta)(1-\alpha) U_{12}+(1-\alpha)^{2} U_{22}<0$.

$$
\frac{d e^{R}}{d e^{R^{*}}}=\frac{(1-\alpha) U_{22}-(1-\beta) U_{21}}{\Delta}>0
$$

if identities complements or independent, $\quad<$ or $>0$ if substitutes.

$$
\frac{d e^{R}}{d e^{S^{*}}}=\frac{-(1-\beta) U_{11}+(1-\alpha) U_{21}}{\Delta}<0
$$

if identities complements or independent, $\quad<$ or $>0$ if substitutes.

$$
\frac{d e^{R}}{d \beta}=\frac{-U_{1}+(1-\beta) U_{11} e^{R}-(1-\alpha) U_{21} e^{R}}{\Delta}>0
$$

if identities complements or independent, $\quad<$ or $>0$ is substitutes.

$$
\frac{d e^{R}}{d \alpha}=\frac{(1-\beta) U_{12}\left(e-e^{R}\right)+U_{2}-(1-\alpha) U_{22}\left(e-e^{R}\right)}{\Delta}<0
$$

if identities complements or independent, $\quad<$ or $>0$ if substitutes.

$$
\frac{d e^{R}}{d \chi}=\frac{\left[(1-\alpha) U_{22}-(1-\beta) U_{21}\right] e^{R *^{\prime}}}{\Delta}<0
$$

if $e^{R^{* \prime}}<0$, identities complements or independent, $<$ or $>0$ if substitutes.

$$
\frac{d e^{R}}{d v}=\frac{\left[-(1-\beta) U_{11}+(1-\alpha) U_{21}\right] e^{S *^{\prime}}}{\Delta}>0
$$

if $e^{S^{* \prime}}<0$, identities complements or independent, $<$ or $>0$ if substitutes. 